\title{
Linking Personality Traits to Objective Foul Records in (Semi-)Professional Youth Basketball
}

\author{
Christoph Schild ${ }^{1}$, Laura J. Botzet ${ }^{2}$, Luca Planert ${ }^{3}$, Karolina A. Ścigała ${ }^{1}$, Ingo Zettler ${ }^{1}$, \\ Jonas W. B. Lang ${ }^{4}$ \\ ${ }^{1}$ University of Copenhagen, Denmark \& University of Siegen, Germany \\ ${ }^{2}$ University of Goettingen, Germany \\ ${ }^{3}$ University of Mannheim, Germany \\ ${ }^{4}$ Ghent University, Belgium \& University of Exeter, UK
}

Author Note

Correspondence concerning this manuscript should be directed to Christoph Schild, Department of Psychology, University of Siegen, Adolf-Reichwein-Str. 2a, 57068. e-mail: christoph.schild@uni-siegen.de.

This investigation was funded by a grant from the Carlsberg Foundation (CF16-0444) to the fifth author. We gratefully thank the NBBL/JBBL (Germany) and Christoph Coura in particular for their help in collecting the data. Note that the NBBL/JBBL had no influence on the research question, analyses, results, or the preparation of this manuscript at all. 


\begin{abstract}
Rule breaking behavior in sports (e.g., fouls) can impact the outcome of games, tournaments, or even whole seasons. Although personality traits have been related to different forms of rule breaking behavior across fields, it has hardly been investigated whether personality traits predict rule breaking behavior in sports. We ran a longitudinal study with 242 (semi-)professional basketball players. Specifically, we measured personality traits prior to the start of the season and official foul statistics per player during the season. Out of the basic personality traits from the HEXACO Model of Personality, Conscientiousness accounted for a substantial amount of variability in the committed/called fouls, whereas no robust relations with other traits or a sportsoriented personality trait (i.e., Sports Mental Toughness) were found.
\end{abstract}

Keywords: basketball; personality traits; fouls; youth sports; HEXACO; sports performance; Sports Mental Toughness 


\section{Linking Personality Traits to Objective Foul Records in (Semi-)Professional Youth}

\section{Basketball}

\section{Introduction \& Theoretical Background}

Rule violation occurs in many areas of human life, such as speeding in traffic (e.g., Alver, Demirel, \& Mutlu, 2014), cheating in admission tests (e.g., Teodorescu \& Andrei, 2009), or misreporting in tax declarations (e.g., Slemrod, Blumenthal, \& Christian, 2001). In sports, foul play (in the following: fouls) represents an important form of rule violation (next to doping, for instance). Although the kinds of fouls can be quite diverse within and across sports (e.g., holding, pulling, tripping), fouls typically come with negative consequences for the fouling person and/or their team. ${ }^{1}$ For example, a team might concede a goal by penalty or free throw, have a successful score overruled, or have a player suspended for the rest of the game. Fouls not only have an immediate impact on the current game (e.g., free kick or points for the opponent team, playing outnumbered), but can also come with long-term consequences (e.g., a player being suspended for the following games). On the other hand, fouls can also provide advantages for the fouling player or team. By conducting a technical foul, for instance, a player can stop the other team from scoring. Additionally, fouls can result in severe injuries of the fouled (as well as the fouling) player (Collins et al., 2008; Fields et al., 2010). Overall, fouls can have a tremendous influence on the outcome of not only a single game, but also an entire season or tournament.

Given the importance of fouls with potential immediate and long-term (dis)advantages for the fouling person and/or team, research has shown that the occurrence of fouls is influenced by situational characteristics of a game. In basketball, for instance, more fouls occur in games between teams with a relatively similar ranking as compared to games between teams with large

\footnotetext{
${ }^{1}$ In the following, we will refer to team sports only.
} 
rank differences (Stulp et al., 2012). Further, more fouls are called on visiting teams (Anderson $\&$ Pierce, 2009) as well as on the team that is leading the game (Anderson \& Pierce, 2009; Price et al., 2012) and/or the series in a playoff set up (Price et al., 2012) . Even referee characteristics, such as height, have been related to foul calls: Shorter referees have been found to call more fouls (the so-called Napoleon complex; Gift \& Rodenberg, 2014).

Importantly, though, the occurrence of fouls is not only affected by situational characteristics affecting all players' behaviors. Data across sports shows that the number of players' fouls is normally distributed which suggests that inter-individual differences between players exist. To illustrate this, Figure 1 shows the variance in fouls for different positions of three important team sport leagues. Specifically, Figure 1a shows the variance in the average number of personal fouls per minute of professional basketball players from the regular National Basketball Association (NBA) season 2017 (data retrieved from https://stats.nba.com/players/). Figure $1 \mathrm{~b}$ shows the variance in personal fouls per game of professional ice hockey players from the National Hockey League (NHL) regular season 2017/2018 (data retrieved from https://www.hockey-reference.com/leagues/NHL_2018_skaters-misc.html). Finally, Figure 1c shows the variance in personal fouls per 90 minutes of professional soccer players from the UEFA Champions League season 2018/2019 (data retrieved from https://www.uefa.com/uefachampionsleague/season=2019/statistics/round=2000980/players/kind $=$ disciplinary/index.html). Across the sports, one can see that specific positions are linked to more or less fouls on average. Importantly, however, positions account only for a limited variance in fouls (e.g., position explains only $13.2 \%$ of variance in fouls per minute for basketball), whereas the variance in personal fouls within different positions is large across sports. Thus, next to situational characteristics of a game applying to all players as well as the 
position of a player, inter-individual differences in general and personality traits in particular are likely to affect whether a player fouls or not.

Personality traits can be defined as "relatively enduring patterns of thoughts, feelings, and behaviors that reflect the tendency to respond in certain ways under certain circumstances" (Roberts, 2009, p. 140). Personality traits are summarized in models of basic personality structure such as the Five-Factor (McCrae \& Costa Jr., 2008) or the HEXACO Model (Ashton et al., 2014; Ashton \& Lee, 2007), which structure the variety of personality traits parsimoniously, yet comprehensively in a few basic trait dimensions. And, indeed, the basic traits from these models have been found to explain a wide array of outcomes to a reasonable degree (Ozer \& Benet-Martínez, 2006; Roberts, Kuncel, Shiner, Caspi, \& Goldberg, 2007; Zettler, Thielmann, Hilbig, \& Moshagen, 2020).
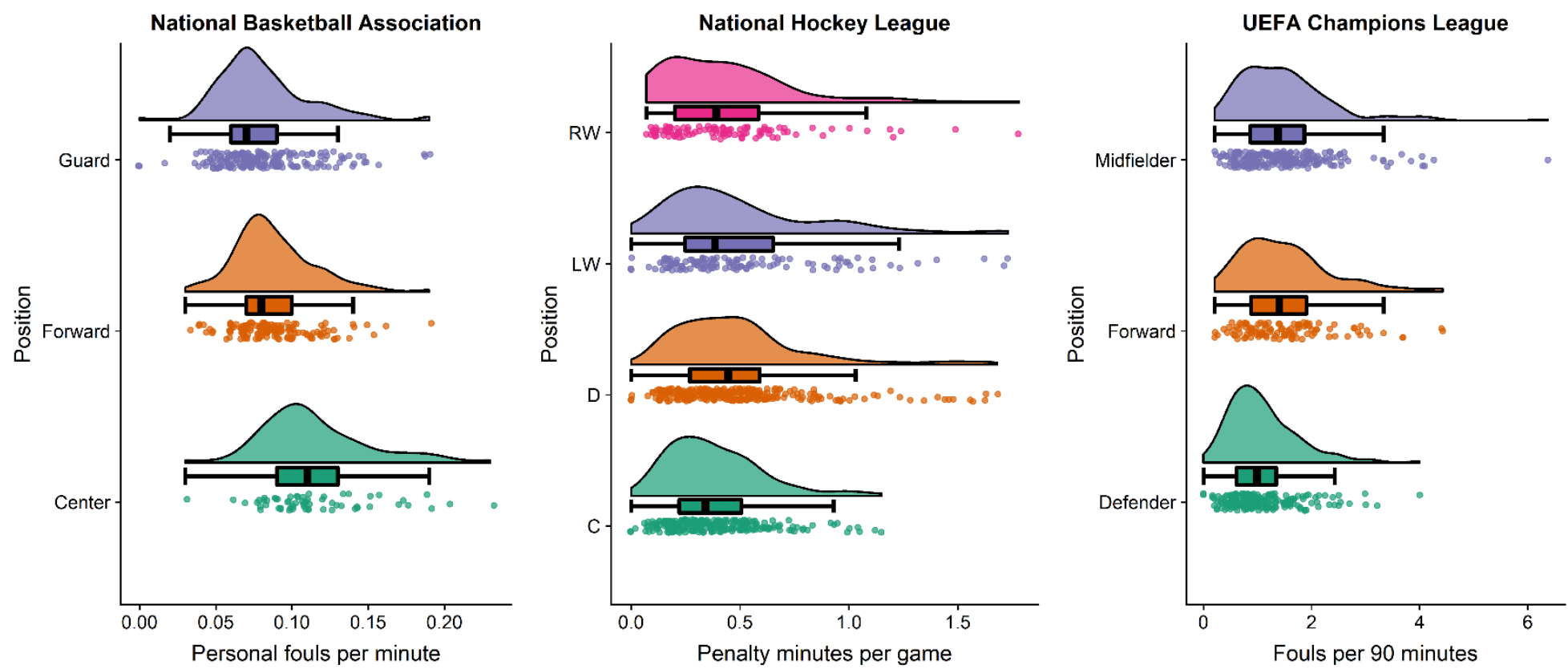

Figure 1. Raincloud plots of fouls for basketball, hockey and soccer. Plots show distributions, boxplots, and densities for different forms of fouls based on position. The left graph shows personal fouls per minute in the National Basketball Association regular season 2017-2018 $(N=$ 
$425)$ by position $\left(n_{\text {Center }}=62, n_{\text {Forward }}=137, n_{\text {Guard }}=196\right)$. Only players that were listed as playing one position only and playing at least 20 minutes in the whole season were included. Data was retrieved from https://stats.nba.com/players/. The middle graph shows penalty minutes per game in the National Hockey League regular season $2017-2018(N=743)$ by position $\left(n_{\text {Center }}\right.$ $\left.=250, n_{\text {Defensemen }}=262, n_{\text {Left Wing }}=125, n_{\text {Right Wing }}=106\right)$. Only players that were listed as playing at a clear position and playing in at least 10 games in the whole season were included. Outliers were dropped for illustration purposes. Data was retrieved from https://www.hockeyreference.com/leagues/NHL_2018_skaters-misc.html. The right graph shows fouls per 90 minutes in the UEFA Champions League season 2018-2019 $(N=515)$ by position $\left(n_{\text {Defender }}=\right.$ $\left.262, n_{\text {Forward }}=125, n_{\text {Midfielder }}=215\right)$. Only players playing at least 90 minutes in the whole season were included. Data was retrieved from

https://www.uefa.com/uefachampionsleague/season=2019/statistics/round=2000980/players/kind =disciplinary/index.html. Plots are based on Allen, Poggiali, Whitaker, Marshall, \& Kievit (2018).

With regard to sports, basic personality traits have been linked to different levels of performance (general athletes vs. professional athletes). For example, studies have found that athletes on a more professional level have lower levels of Neuroticism, and higher levels of Agreeableness and Conscientiousness as compared to less professional athletes (see Allen et al., 2013 for a review). A rather similar pattern was found for (sports) mental toughness, a sportsoriented trait that measures confidence and resilience. Here, professional athletes showed higher levels of mental toughness than non-professional athletes (male martial art athletes: Chen \& Cheesman, 2013; athletes in general: Cowden, 2017).

Concerning athletes of the same level, different basic personality traits - and especially higher levels of Conscientiousness - have been found to be related to performance (female soccer players: Piedmont, Hill, \& Blanco, 1999; male soccer players: Teshome, Mengistu, \& Beker, 2015; male hockey players: Conway, 2016). Similarly, mental toughness has been found to correlate positively with performance (male and female basketball players: Cowden, 2017; Newland, Newton, Finch, Harbke, \& Podlog, 2013). Next to direct effects of personality traits on performance, some studies reported interaction effects with situational characteristics. For 
example, Narcissism was found to moderate the effect of high pressure on performance in a way that people high in Narcissism perform better under high pressure (Roberts, Woodman, Hardy, Davis, \& Wallace, 2013; Roberts, Woodman, \& Sedikides, 2018).

In line with the consistent links between personality traits and behavioral outcomes, various behaviors conceptually similar to fouls have been shown to be predicted by personality traits, such as accident involvement (Clarke \& Robertson, 2005, 2008), counterproductive work behaviors (Anglim et al., 2018; Marcus et al., 2007), or dishonest behaviors (Pfattheicher et al., 2018; Ścigała et al., 2018). Interestingly, though, studies linking personality traits to rule breaking behaviors in sport are almost absent. Although a few studies investigated the relation between personality traits and attitudes towards doping in athletes (Nicholls et al., 2017; Petróczi, 2007), to the best of our knowledge only two studies have reported relations between different personality traits and fouls (Bushman \& Wells, 1998; Gee et al., 2010). In detail, Bushman and Wells (1998) found a significant relation between trait physical aggressiveness and aggressive penalties (e.g., fighting, slashing, tripping) in a sample of 91 male hockey players, and Gee et al. (2010) found a positive relation between the Comfort with Conflict scale of the "SportsPro"TM" (Marshall, 1979) and total penalty minutes in a sample of 49 male hockey players. Whereas these studies provide first insights, both studies did not look at (more widely used) basic personality traits and relied on relatively small sample sizes, potentially limiting (generalizable) conclusions.

In summary, fouls in sports and how this behavior is related to inter-individual characteristics is understudied. Given the importance of fouls and the consistent links between personality and several behavioral outcomes that show parallels with fouls, we conducted a 
longitudinal study investigating the relations between basic personality traits, mental toughness, and fouls in a sample of 242 (semi-)professional youth male basketball players.

\section{The Present Investigation}

The present investigation aims to shed light on the relation between personality traits and fouls in sports. To this end, we relied on two personality measures. First, we used the HEXACO60 (Ashton \& Lee, 2009; Moshagen et al., 2019), a personality questionnaire with 60 items which measures the six basic personality trait dimensions of the HEXACO model: HonestyHumility, Emotionality, Extraversion, Agreeableness, Conscientiousness, and Openness to Experience (in the following: Openness; Ashton \& Lee, 2007). Similar to the more widely known Big Five/Five-Factor model (which we use interchangeable herein), the HEXACO model was derived via the lexical approach (e.g., Ashton et al., 2004). The HEXACO dimensions of Conscientiousness, Extraversion and Openness basically overlap with the respective Big Five counterparts (e.g., Ashton, Lee, \& Visser, 2019). Further, HEXACO Agreeableness vs Anger and Emotionality overlap considerably with their Big Five counterparts (Agreeableness and Neuroticism, respectively) - however, with some differences in the defining content of the factors. Finally, the most prominent difference between both models is the presence of a sixth dimension in the HEXACO model. This sixth dimension, Honesty-Humility, has been shown to be especially relevant in contexts of prosocial and antisocial behaviors (e.g., Ashton \& Lee, 2007; Ashton et al., 2014, 2019; Muris, Merckelbach, Otgaar, \& Meijer, 2017; Pletzer et al., 2019; Zettler et al., 2020). ${ }^{2}$ Importantly, HEXACO traits are defined by adjectives that can easily be related to rule violation behaviors in sports (see, e.g., Table 1 based on Ashton \& Lee, 2007).

\footnotetext{
${ }^{2}$ For discussion about whether Honesty-Humility is adequately captured by Big Five measures see, e.g., Ashton \& Lee, (2019, 2020), Miller et al. (2011) and Vize et al. (2020).
} 
Second, we used the Sports Mental Toughness Questionnaire (SMTQ; Sheard, Golby, \& Van Wersch, 2009) which measures mental toughness explicitly tailored to the sports domain via three characteristic main components: Confidence (vs. Self-doubt), Constancy (vs. Irresolute), and Control (vs. Agitation). Again, these characteristics can be seen as relevant in the context of fouls. For example, a player who is highly confident, constant and in control of their actions and emotions might commit less fouls than a player who is not confident, inconstant and strongly influenced by their emotions.

Table 1.

Examples of positively and negatively defining adjectives for all six dimensions of the HEXACO Personality Inventory: Honesty-Humility, Emotionality, Extraversion, Agreeableness vs Anger, Conscientiousness, Openness to Experience (based on Ashton \& Lee, 2007).

\begin{tabular}{ccc}
\hline Dimension & Positively Defining Adjectives & Negatively Defining Adjectives \\
\hline Honesty-Humility & $\begin{array}{c}\text { sincere, honest, faithful/loyal } \\
\text { emotional, oversensitive, } \\
\text { sentimental }\end{array}$ & sly, greedy, pretentious \\
bxtraversion & outgoing, lively, extraverted & shy, passive, withdrawn \\
Agreeableness vs & patient, tolerant, peaceful & ill-tempered, quarrelsome, choleric \\
Conscientiousness & organized, careful, precise & sloppy, reckless, irresponsible \\
Openness to & intellectual, creative, & shallow, unimaginative, \\
Experience & unconventional & conventional \\
\hline
\end{tabular}

Finally, we linked both personality measures to objective foul records of (semi-)professional youth male basketball players. No hypotheses were preregistered before data collection and thus the presented analyses and results are seen as exploratory. 


\section{Methods}

Participants. For this research, we worked together with the Nachwuchs und Jugend Basketball Bundesliga (NBBL/JBBL), which organizes the top-level youth basketball league for under 19 year olds in Germany. In the season 2017, the leagues consisted of 90 teams with 1,480 players overall. Importantly, the teams are nested in leagues. More precisely, first, some teams (34) played in the NBBL (which is for players under the age of 19), whereas the remaining teams (56) played in the JBBL (which is for players under the age of 16). Then, both leagues-NBBL and JBBL_ — use a two-phase format. In the first phase, the leagues are grouped into subleagues based on geographical distance, so that teams only play against other teams which are (geographically) somewhat close; there were 4 subleagues in the NBBL and 8 subleagues in the JBBL. After the first phase, the subleagues are grouped based on performance into higher tier and lower tier subleagues ( 2 in the NBBL and 8 in the JBBL). The purpose of this format us to increase competition in the second phase of the season.

Being part of a research project on basketball and personality in general, this study was approved by the Institutional Review Board of the University of Copenhagen. 242 male players (mean age $=15.13$ (ranging from 14 to 18$), S D=1.24$ years) from 58 different teams (39 JBBL, 19 NBBL) participated in an online survey administered via formr (formr.org; Arslan \& Tata, 2019; Arslan, Walther, \& Tata, 2019) prior to season 2017/2018, up to one day before the season started. The link to the study was shared via the official NBBL/JBBL website and also distributed via email to managers and coaches of all 90 teams. Participation in the survey differed across teams with some teams not participating at all and others having up to 15 players participating. Importantly, participants and non-participants did not differ regarding fouls per 
minute $(t(308.28)=1.55, p=.121)$ and position $\left(X^{2}(4)=0.70, p=.951\right)$. However, participants were younger than non-participants $(t(378.72)=-3.52, p<.001)$.

\section{Measures and procedure}

Participants first provided demographic information, which included their name, age, position, and team. This information allowed us to link questionnaire data to actual performance data. Participants then filled out the German (Moshagen et al., 2014) 60-item version of the HEXACO Personality Inventory-Revised (HEXACO-60; Ashton \& Lee, 2009; Moshagen et al., 2019) and a self-translated German version of the SMTQ (Sheard et al., 2009). Responses on the questionnaires were given on a 5-point Likert Scale ranging from 'strongly disagree' to 'strongly agree', and mean factor scores for each participant were computed for each dimension (by reversing negative pooled items and averaging the Likert Scale responses). The order of the questionnaires and the item order therein were randomized. An attention check item ("Please indicate " 1 " if you are reading carefully") was interspersed in the items. Please note that other questionnaires were also administered, which are, however, not relevant for this study. Descriptives of and correlations between the personality traits can be found in Table 2 . 


\section{Table 2.}

Means, Standard Deviations and intercorrelations of the personality variables.

\begin{tabular}{|c|c|c|c|c|c|c|c|c|c|c|c|c|}
\hline Trait & $M$ & $S D$ & $\mathrm{HH}$ & EM & EX & $\mathrm{AG}$ & $\mathrm{CO}$ & $\mathrm{OP}$ & Conf & Cons & Cont & $\mathrm{Pf}$ \\
\hline Honesty-Humility (HH) & 3.37 & 0.62 & .66 & & & & & & & & & \\
\hline Emotionality (EM) & 2.76 & 0.53 & .06 & .65 & & & & & & & & \\
\hline Extraversion (EX) & 3.66 & 0.54 & -.02 & .01 & .72 & & & & & & & \\
\hline Agreeableness (AG) & 3.35 & 0.54 & .31 & .03 & -.03 & .67 & & & & & & \\
\hline Conscientiousness (CO) & 3.45 & 0.59 & .10 & .02 & .10 & .03 & .74 & & & & & \\
\hline Openness (OP) & 2.85 & 0.57 & -.04 & -.06 & .14 & -.06 & .09 & .64 & & & & \\
\hline Confidence (Conf) & 3.64 & 0.53 & .01 & -.14 & .38 & -.14 & .23 & .17 & .64 & & & \\
\hline Constancy (Cons) & 4.18 & 0.55 & .16 & -.06 & .20 & .09 & .44 & .09 & .50 & .50 & & \\
\hline Control (Cont) & 3.13 & 0.75 & .05 & -.33 & .27 & .11 & .03 & -.06 & .29 & .20 & .60 & \\
\hline Fouls per minute $(\mathrm{Pf})$ & 0.11 & 0.07 & .01 & .02 & .06 & -.03 & -.20 & -.04 & .03 & -.04 & -.01 & - \\
\hline
\end{tabular}

Note: Correlations with $\mathrm{p}$ values $<.05$ are presented in bold. Cronbach's alpha estimates of the personality measures are displayed in the diagonal.

After the season, the NBBL/JBBL provided us with the relevant performance data of each player. This included personal fouls, minutes played, team, and league (NBBL or JBBL). Questionnaire data and performance data was then merged into a final dataset.

\section{Analyses and Results}

As in the data of the NBA, personal fouls per minute do strongly vary in the NBBL/JBBL in general. However, personal fouls were only weakly related to players' positions (marginal $R^{2}$ $=3.35 \%$ ) as illustrated in Figure 2 . 


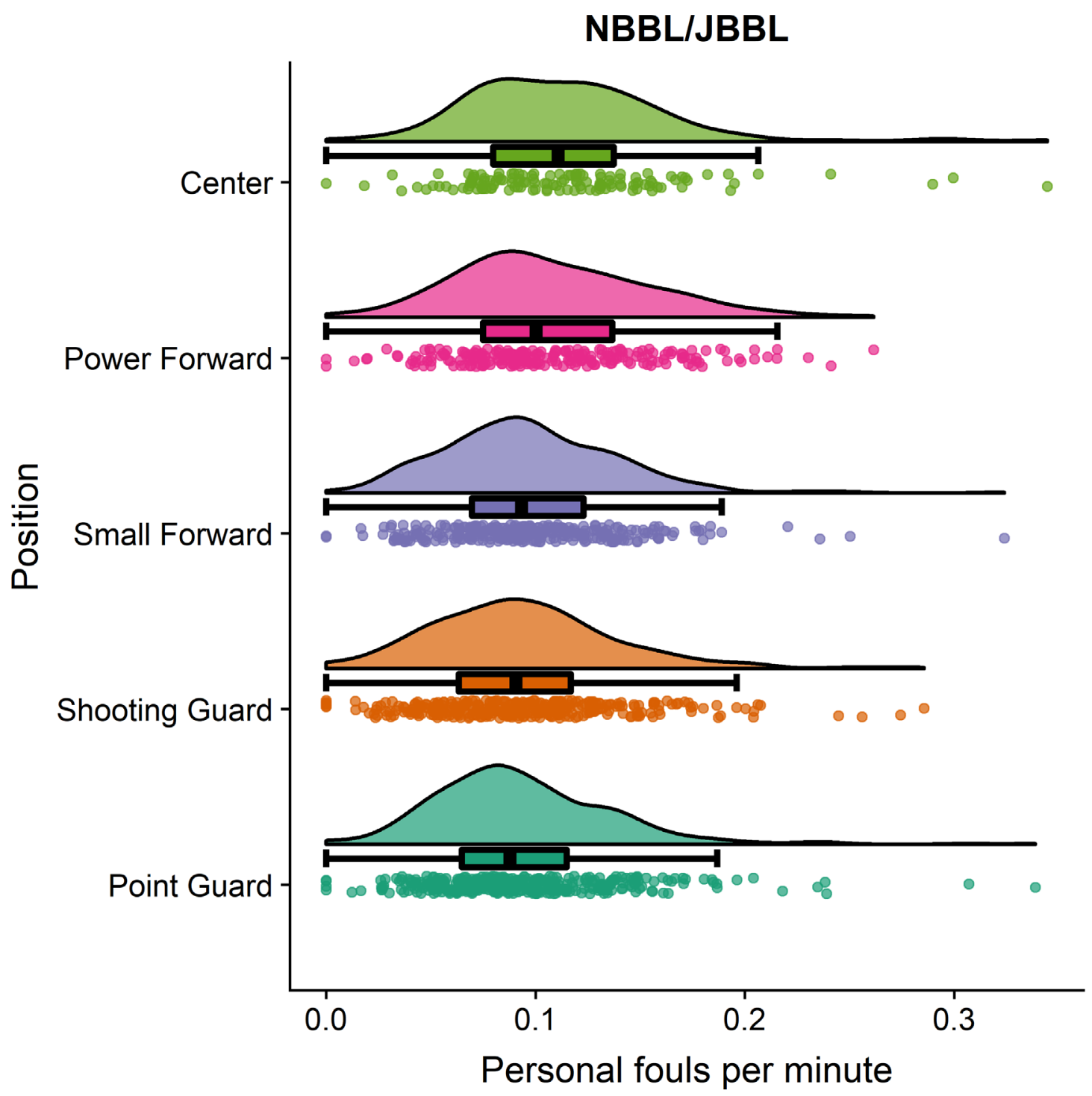

Figure 2. Raincloud plot of personal fouls per minute in the NBBL/JBBL season 2017/2018. The plot includes distributions, boxplots, and densities for different forms of fouls based on position $\left(n_{\text {Center }}=132, n_{\text {Power Forward }}=226, n_{\text {Small Forward }}=288, n_{\text {Shooting Guard }}=332, n_{\text {Point Guard }}=361\right)$. Only players which played at least 20 minutes during the season were included for illustration purposes.

In order to account for the nature of personal fouls (i.e., count data), for the nested structure of our data (i.e., players were nested in teams and leagues), and for overdispersion (see Bolker et al., 2009; Harrison, 2014, 2015), we ran three Poisson generalized linear mixed-effects models (GLMMs) with two random factors: observation and team, predicting the number of 
personal fouls: The first model with HEXACO traits as fixed effects, the second model with SMTQ traits as fixed effects, and the third model with both HEXACO and SMTQ traits as fixed effects. We further included fixed effects for league (NBBL or JBBL) and position (backcourt vs. frontcourt) in all models.

Across the GLMMs (Table 3), we found that Conscientiousness and Openness significantly predicted personal fouls. Specifically, people high in Conscientiousness were less likely to commit personal fouls than people low in Conscientiousness, whereas people high in Openness were more likely to commit personal fouls as compared to people low in Openness. The remaining HEXACO and the Sports Mental Toughness traits did not predict personal fouls significantly. Importantly, and in line with the correlational results, Openness was found to be a significant predictor only when other traits were controlled for. When Openness was the only fixed effect in the model (in addition to observation- and team-level random effects), it lost its significance $($ Estimate $=0.05,95 \% \mathrm{CI}=-0.01-0.10, p=.082)$. No other model including single traits indicated differing results from the models including all HEXACO or SMTQ traits (see Supplementary Material).

To provide further insights into which personality facets might drive the relation between Conscientiousness and personal fouls, we ran a Poisson GLMM including two random factors (observation and team), and the four facets of Conscientiousness (Organization, Diligence, Perfectionism, and Prudence). Prudence turned out to be the only significant predictor (Estimate $=-0.11,95 \% \mathrm{CI}=-0.16--0.05, p<.001)$. Note, however, that interpretations on the facet-level should be considered with caution when using the HEXACO-60 (see, e.g., Ashton \& Lee, 2009). 
Table 3.

Poisson generalized linear mixed-effects models including observation- and team-level random effects predicting the number of personal fouls.

\section{Personal fouls}

\begin{tabular}{|c|c|c|c|c|c|c|c|c|c|}
\hline Predictors & Estimate & $95 \% C I$ & $p$ & Estimate & $95 \% C I$ & $p$ & Estimate & $95 \% C I$ & $p$ \\
\hline Intercept & 1.51 & $1.43-1.59$ & $<.001$ & 1.49 & $1.41-1.57$ & $<.001$ & 1.51 & $1.43-1.59$ & $<.001$ \\
\hline League & -0.07 & $-0.19-0.05$ & .261 & -0.07 & $-0.19-0.06$ & .289 & -0.07 & $-0.20-0.05$ & .230 \\
\hline Position & 0.04 & $-0.07-0.15$ & .456 & 0.08 & $-0.02-0.19$ & .133 & 0.04 & $-0.07-0.15$ & .492 \\
\hline Honesty-Humility & -0.00 & $-0.06-0.05$ & .891 & & & & -0.00 & $-0.06-0.05$ & .916 \\
\hline Emotionality & -0.01 & $-0.06-0.04$ & .808 & & & & -0.01 & $-0.06-0.05$ & .851 \\
\hline Extraversion & 0.03 & $-0.02-0.08$ & .317 & & & & 0.03 & $-0.03-0.08$ & .362 \\
\hline Agreeableness & -0.02 & $-0.08-0.03$ & .364 & & & & -0.02 & $-0.08-0.03$ & .414 \\
\hline Conscientiousness & -0.09 & $-0.14--0.04$ & .001 & & & & -0.09 & $-0.15--0.03$ & .002 \\
\hline Openness & 0.05 & $0.00-0.11$ & .044 & & & & 0.06 & $0.00-0.11$ & .044 \\
\hline Confidence & & & & 0.02 & $-0.04-0.08$ & .454 & 0.00 & $-0.06-0.06$ & .977 \\
\hline Constancy & & & & -0.04 & $-0.11-0.02$ & .173 & -0.00 & $-0.07-0.07$ & .980 \\
\hline Control & & & & 0.00 & $-0.05-0.06$ & .959 & 0.00 & $-0.06-0.06$ & .961 \\
\hline Random Effects & & & & & & & & & \\
\hline$\tau_{00}$ & \multicolumn{2}{|l|}{0.09 observation } & & \multicolumn{2}{|c|}{0.10 observation } & & \multicolumn{2}{|c|}{0.09 observation } & \\
\hline$\mu_{00}$ & \multicolumn{2}{|l|}{0.00 team } & & \multicolumn{2}{|l|}{0.00 team } & & \multicolumn{2}{|l|}{0.00 team } & \\
\hline $\mathrm{R}^{2}$ GLMM & \multicolumn{2}{|l|}{0.086} & & \multicolumn{2}{|l|}{0.028} & & \multicolumn{2}{|l|}{0.088} & \\
\hline
\end{tabular}

Note: $p$ values $<.05$ are presented in bold. League $(\mathrm{JBBL}=0 ; \mathrm{NBBL}=1)$, Position $(0=$ Backcourt; Frontcourt $=1)$. $\mathrm{R}^{2} \mathrm{GLMM}$ as described in Nakagawa et al. (2017) 


\section{Discussion}

This study investigated whether personality traits, namely the HEXACO and SMTQ traits, predict official foul statistics in (semi-)professional youth male basketball players. In a sample of 242 players, Conscientiousness was found to significantly predict personal fouls: Players with higher levels of Conscientiousness were consistently less likely to commit personal fouls. Players in the bottom quartile of Conscientiousness scores conduct 1.24 fouls in ten minutes play time, while players in the top quartile conduct 0.95 fouls in ten minute play time (thus, players in the bottom quartile of $\mathrm{C}$ conduct approx. $30 \%$ more fouls than players in the top quartile). Openness to Experience was inconsistently linked to personal fouls across analyses. No other traits significantly predicted personal fouls.

Importantly, these results are in line with the defining characteristics of the Conscientiousness trait (organized, careful, precise vs. sloppy, reckless, irresponsible) and its links to similar outcomes such as counterproductive work behavior (Anglim et al., 2018; Zettler et al., 2020) and job performance (Hurtz \& Donovan, 2000). Further, our findings add to previous studies that have linked Conscientiousness to sports performance (e.g., Conway, 2016; Piedmont et al., 1999).

Exploratory analyses on the facets of Conscientiousness showed that Prudence was the main driver of the relation between Conscientiousness and personal fouls. Intuitively this finding makes sense as Prudence captures a tendency to deliberate carefully and to inhibit impulses. However, future research should aim to more deeply delve into his exploratory finding, also because we only used a very brief inventory to look at the HEXACO facets.

The remaining four dimensions of the HEXACO model-Honesty-Humility, Emotionality, Extraversion, and Agreeableness - were not significantly related to personal fouls, 
which might be rather surprising for some traits in particular. For example, Honesty-Humility could have been assumed to be linked to fouls given that it is generally linked to rule breaking behavior (Heck et al., 2018; Schild et al., 2019). In a similar vein, the sports-oriented questionnaire did not significantly predict number of personal fouls, implying that Confidence, Constancy, and Control as measured by the SMTQ, are not relevant in describing interindividual differences predicting fouls (in German semi-professional basketball youth sports).

Given the importance of fouls across sports, these results might provide important insights for future research and practice. First, researchers could investigate whether our results can be transferred to other sports and other populations. Second, if similar results are obtained, sport teams and managers might base their decision-making processes stronger on players' personality characteristics, especially their levels in Conscientiousness. This said, our investigation is of course limited by the exploratory nature and a young male only sample in one sport only and in one country only. Future studies should thus aim to replicate and further extend these findings, ideally in pre-registered investigations. Lastly, our data does also not differentiate between different kinds of fouls, which are typically classified (e.g., personal fouls, technical fouls). Arguably some fouls can be classified as clever or strategic, and thus might even provide benefits for the fouling team. Other fouls, however, might be seen as unnecessary or sloppy and might thus lead to negative outcomes for the fouling team. Thus, future studies could try to disentangle different kinds of fouls and how they relate to personality traits.

\section{Data availability}

Given that the data cannot be anonymized (performance scores of the players are/were public), data cannot be shared publicly. However, researchers can contact the corresponding author to request further exploratory analyses. 


\section{Preregistration}

The data collection was preregistered: https://osf.io/z8qgv

No specific hypotheses were pre-registered.

\section{Author Contributions}

C.S., L.P., K.A.Ś, J.W.B.L, and I.Z. contributed to the study design. Testing and data collection were performed by C.S. and I.Z. C.S., L.J.B., and J.W.B.L. performed the data analysis. All authors performed the interpretation of the data. C.S. drafted the manuscript, and

L.J.B., L.P., K.A.Ś, J.W.B.L., and I.Z. provided critical revisions. All authors approved the final version of the manuscript for submission. 


\section{References}

Allen, M., Poggiali, D., Whitaker, K., Marshall, T. R., \& Kievit, R. (2018). Raincloud plots: A multi-platform tool for robust data visualization (e27137v1). PeerJ Inc. https://doi.org/10.7287/peerj.preprints.27137v1

Allen, M. S., Greenlees, I., \& Jones, M. (2013). Personality in sport: A comprehensive review. International Review of Sport and Exercise Psychology, 6(1), 184-208. https://doi.org/10.1080/1750984X.2013.769614

Alver, Y., Demirel, M. C., \& Mutlu, M. M. (2014). Interaction between socio-demographic characteristics: Traffic rule violations and traffic crash history for young drivers. Accident Analysis \& Prevention, 72, 95-104. https://doi.org/10.1016/j.aap.2014.06.015

Anderson, K. J., \& Pierce, D. A. (2009). Officiating bias: The effect of foul differential on foul calls in NCAA basketball. Journal of Sports Sciences, 27(7), 687-694. https://doi.org/10.1080/02640410902729733

Anglim, J., Lievens, F., Everton, L., Grant, S. L., \& Marty, A. (2018). HEXACO personality predicts counterproductive work behavior and organizational citizenship behavior in lowstakes and job applicant contexts. Journal of Research in Personality, 77, 11-20. https://doi.org/10.1016/j.jrp.2018.09.003

Arslan, R. C., \& Tata, C. (2019). Chain simple forms / surveys into longer runs using the power of $R$ to generate pretty feedback and complex designs https://formr.org. Zenodo. https://doi.org/10.5281/zenodo.3229668 
Arslan, R. C., Walther, M. P., \& Tata, C. S. (2019). formr: A study framework allowing for automated feedback generation and complex longitudinal experience-sampling studies using R. Behavior Research Methods. https://doi.org/10.3758/s13428-019-01236-y

Ashton, M. C., \& Lee, K. (2007). Empirical, Theoretical, and Practical Advantages of the HEXACO Model of Personality Structure. Personality and Social Psychology Review, 11(2), 150-166. https://doi.org/10.1177/1088868306294907

Ashton, M. C., \& Lee, K. (2009). The HEXACO-60: A Short Measure of the Major Dimensions of Personality. Journal of Personality Assessment, 91(4), 340-345. https://doi.org/10.1080/00223890902935878

Ashton, M. C., \& Lee, K. (2019). How Well Do Big Five Measures Capture HEXACO Scale Variance? Journal of Personality Assessment, 101(6), 567-573. https://doi.org/10.1080/00223891.2018.1448986

Ashton, M. C., \& Lee, K. (2020). Objections to the HEXACO Model of Personality StructureAnd Why Those Objections Fail. European Journal of Personality, n/a(n/a), Article n/a. https://doi.org/10.1002/per.2242

Ashton, M. C., Lee, K., \& de Vries, R. E. (2014). The HEXACO Honesty-Humility, Agreeableness, and Emotionality Factors: A Review of Research and Theory. Personality and Social Psychology Review, 18(2), 139-152. https://doi.org/10.1177/1088868314523838

Ashton, M. C., Lee, K., \& Visser, B. A. (2019). Where's the H? Relations between BFI-2 and HEXACO-60 scales. Personality and Individual Differences, 137, 71-75. https://doi.org/10.1016/j.paid.2018.08.013 
Bolker, B. M., Brooks, M. E., Clark, C. J., Geange, S. W., Poulsen, J. R., Stevens, M. H. H., \& White, J.-S. S. (2009). Generalized linear mixed models: A practical guide for ecology and evolution. Trends in Ecology \& Evolution, 24(3), 127-135. https://doi.org/10.1016/j.tree.2008.10.008

Bushman, B. J., \& Wells, G. L. (1998). Trait aggressiveness and hockey penalties: Predicting hot tempers on the ice. Journal of Applied Psychology, 83(6), 969-974. https://doi.org/10.1037/0021-9010.83.6.969

Chen, M. A., \& Cheesman, D. J. (2013). Mental Toughness of Mixed Martial Arts Athletes at Different Levels of Competition. Perceptual and Motor Skills, 116(3), 905-917. https://doi.org/10.2466/29.30.PMS.116.3.905-917

Clarke, S., \& Robertson, I. (2005). A meta-analytic review of the Big Five personality factors and accident involvement in occupational and non-occupational settings. Journal Of Occupational And Organizational Psychology, 78(3), 355-376. https://doi.org/10.1348/096317905X26183

Clarke, S., \& Robertson, I. (2008). An Examination of the Role of Personality in Work Accidents Using Meta-analysis. Applied Psychology, 57(1), 94-108. https://doi.org/10.1111/j.1464-0597.2007.00267.x

Collins, C. L., Fields, S. K., \& Comstock, R. D. (2008). When the rules of the game are broken: What proportion of high school sports-related injuries are related to illegal activity? Injury Prevention, 14(1), 34-38. https://doi.org/10.1136/ip.2007.017277

Conway, B. (2016). Investigating the relationship between personality traits and athletic performance among elite hockey players. EWU Masters Thesis Collection. https://dc.ewu.edu/theses/347 
Cowden, R. G. (2017). Mental Toughness and Success in Sport: A Review and Prospect. The Open Sports Sciences Journal, 10(1). https://doi.org/10.2174/1875399X01710010001

Fields, S. K., Collins, C. L., \& Comstock, R. D. (2010). Violence in youth sports: Hazing, brawling and foul play. British Journal of Sports Medicine, 44(1), 32-37. https://doi.org/10.1136/bjsm.2009.068320

Gee, C. J., Marshall, J. C., \& King, J. F. (2010). Should coaches use personality assessments in the talent identification process? A 15 year predictive study on professional hockey players. International Journal of Coaching Science, 4(1), 25-34.

Gift, P., \& Rodenberg, R. M. (2014). Napoleon Complex: Height Bias Among National Basketball Association Referees. Journal of Sports Economics, 15(5), 541-558. https://doi.org/10.1177/1527002514535168

Harrison, X. A. (2014). Using observation-level random effects to model overdispersion in count data in ecology and evolution. PeerJ, 2, e616. https://doi.org/10.7717/peerj.616

Harrison, X. A. (2015). A comparison of observation-level random effect and Beta-Binomial models for modelling overdispersion in Binomial data in ecology \& evolution. PeerJ, 3, e1114. https://doi.org/10.7717/peerj.1114

Heck, D. W., Thielmann, I., Moshagen, M., \& Hilbig, B. E. (2018). Who lies? A large-scale reanalysis linking basic personality traits to unethical decision making. Judgment and Decision Making, 13(4), 356-371.

Hurtz, G. M., \& Donovan, J. J. (2000). Personality and job performance: The Big Five revisited. Journal of Applied Psychology, 85(6), 869-879. https://doi.org/10.1037/00219010.85.6.869 
Marcus, B., Lee, K., \& Ashton, M. C. (2007). Personality Dimensions Explaining Relationships Between Integrity Tests and Counterproductive Behavior: Big Five, or One in Addition? Personnel Psychology, 60(1), 1-34. https://doi.org/10.1111/j.1744-6570.2007.00063.x

Marshall, J. (1979). SportsPro Validation Manual. Toronto, Canada: Selection Testing Consultants International.

McCrae, R. R., \& Costa Jr., P. T. (2008). Empirical and theoretical status of the five-factor model of personality traits. In The SAGE handbook of personality theory and assessment, Vol 1: Personality theories and models (pp. 273-294). Sage Publications, Inc. https://doi.org/10.4135/9781849200462.n13

Miller, J. D., Gaughan, E. T., Maples, J., \& Price, J. (2011). A Comparison of Agreeableness Scores From the Big Five Inventory and the NEO PI-R: Consequences for the Study of Narcissism and Psychopathy. Assessment, 18(3), 335-339. https://doi.org/10.1177/1073191111411671

Moshagen, M., Hilbig, B. E., \& Zettler, I. (2014). Faktorenstruktur, psychometrische Eigenschaften und Messinvarianz der deutschsprachigen Version des 60-Item HEXACO Persönlichkeitsinventars. Diagnostica, 60(2), 86-97. https://doi.org/10.1026/0012$1924 / \mathrm{a} 000112$

Moshagen, M., Thielmann, I., Hilbig, B. E., \& Zettler, I. (2019). Meta-Analytic Investigations of the HEXACO Personality Inventory(-Revised). Zeitschrift für Psychologie, 227(3), 186194. https://doi.org/10.1027/2151-2604/a000377

Muris, P., Merckelbach, H., Otgaar, H., \& Meijer, E. (2017). The Malevolent Side of Human Nature: A Meta-Analysis and Critical Review of the Literature on the Dark Triad 
(Narcissism, Machiavellianism, and Psychopathy). Perspectives on Psychological Science, 12(2), 183-204. https://doi.org/10.1177/1745691616666070

Nakagawa, S., Johnson, P. C. D., \& Schielzeth, H. (2017). The coefficient of determination R2 and intra-class correlation coefficient from generalized linear mixed-effects models revisited and expanded. Journal of The Royal Society Interface, 14(134), 20170213. https://doi.org/10.1098/rsif.2017.0213

NBA (2019, June). Retrieved from https://stats.nba.com/players/.

Newland, A., Newton, M., Finch, L., Harbke, C. R., \& Podlog, L. (2013). Moderating variables in the relationship between mental toughness and performance in basketball. Journal of Sport and Health Science, 2(3), 184-192. https://doi.org/10.1016/j.jshs.2012.09.002

Nicholls, A. R., Madigan, D. J., Backhouse, S. H., \& Levy, A. R. (2017). Personality traits and performance enhancing drugs: The Dark Triad and doping attitudes among competitive athletes. Personality and Individual Differences, 112, 113-116.

https://doi.org/10.1016/j.paid.2017.02.062

Ozer, D. J., \& Benet-Martínez, V. (2006). Personality and the Prediction of Consequential Outcomes. Annual Review of Psychology, 57(1), 401-421. https://doi.org/10.1146/annurev.psych.57.102904.190127

Petróczi, A. (2007). Attitudes and doping: A structural equation analysis of the relationship between athletes' attitudes, sport orientation and doping behaviour. Substance Abuse Treatment, Prevention, and Policy, 2(1), 34. https://doi.org/10.1186/1747-597X-2-34

Pfattheicher, S., Schindler, S., \& Nockur, L. (2018). On the impact of Honesty-Humility and a cue of being watched on cheating behavior. Journal of Economic Psychology. https://doi.org/10.1016/j.joep.2018.06.004 
Piedmont, R. L., Hill, D. C., \& Blanco, S. (1999). Predicting athletic performance using the fivefactormodel of personality. Personality and Individual Differences, 27(4), 769-777.

Pletzer, J. L., Bentvelzen, M., Oostrom, J. K., \& de Vries, R. E. (2019). A meta-analysis of the relations between personality and workplace deviance: Big Five versus HEXACO. Journal of Vocational Behavior, 112, 369-383. https://doi.org/10.1016/j.jvb.2019.04.004

Price, J., Remer, M., \& Stone, D. F. (2012). Subperfect Game: Profitable Biases of NBA Referees. Journal of Economics \& Management Strategy, 21(1), 271-300. https://doi.org/10.1111/j.1530-9134.2011.00325.x

Roberts, B. W. (2009). Back to the future: Personality and Assessment and personality development. Journal of Research in Personality, 43(2), 137-145. https://doi.org/10.1016/j.jrp.2008.12.015

Roberts, B. W., Kuncel, N. R., Shiner, R., Caspi, A., \& Goldberg, L. R. (2007). The Power of Personality: The Comparative Validity of Personality Traits, Socioeconomic Status, and Cognitive Ability for Predicting Important Life Outcomes. Perspectives on Psychological Science, 2(4), 313-345. https://doi.org/10.1111/j.1745-6916.2007.00047.x

Roberts, R., Woodman, T., Hardy, L., Davis, L., \& Wallace, H. M. (2013). Psychological Skills Do Not Always Help Performance: The Moderating Role of Narcissism. Journal of Applied Sport Psychology, 25(3), 316-325. https://doi.org/10.1080/10413200.2012.731472

Roberts, R., Woodman, T., \& Sedikides, C. (2018). Pass me the ball: Narcissism in performance settings. International Review of Sport and Exercise Psychology, 11(1), 190-213. https://doi.org/10.1080/1750984X.2017.1290815 
Schild, C., Stern, J., \& Zettler, I. (2019). Linking men's voice pitch to actual and perceived trustworthiness across domains. Behavioral Ecology. https://doi.org/10.1093/beheco/arz173

Ścigała, K. A., Schild, C., Heck, D. W., \& Zettler, I. (2018). Who Deals With the Devil? Interdependence, Personality, and Corrupted Collaboration. Social Psychological and Personality Science, 1948550618813419. https://doi.org/10.1177/1948550618813419

Sheard, M., Golby, J., \& Van Wersch, A. (2009). Progress toward construct validation of the Sports Mental Toughness Questionnaire (SMTQ). European Journal of Psychological Assessment, 25(3), 186-193.

Slemrod, J., Blumenthal, M., \& Christian, C. (2001). Taxpayer response to an increased probability of audit: Evidence from a controlled experiment in Minnesota. Journal of Public Economics, 79(3), 455-483. https://doi.org/10.1016/S0047-2727(99)00107-3

Stulp, G., Kordsmeyer, T., Buunk, A. P., \& Verhulst, S. (2012). Increased aggression during human group contests when competitive ability is more similar. Biology Letters, 8(6), 921-923. https://doi.org/10.1098/rsbl.2012.0591

Teodorescu, D., \& Andrei, T. (2009). Faculty and peer influences on academic integrity: College cheating in Romania. Higher Education, 57(3), 267-282. https://doi.org/10.1007/s10734008-9143-3

Teshome, B., Mengistu, S., \& Beker, G. (2015). The Relationship between Personality Trait and Sport Performance: The Case of National League Football Clubs in Jimma Town, Ethiopia. Journal of Tourism, Hospitality and Sports, 11. 
UEFA (2019, June). Retrieved from https://www.uefa.com/uefachampionsleague/season=2019/statistics/round=2000980/play ers/kind=disciplinary/index.html.

Vize, C. E., Collison, K. L., Miller, J. D., \& Lynam, D. R. (2020). The “core” of the dark triad: A test of competing hypotheses. Personality Disorders, 11(2), 91-99. https://doi.org/10.1037/per0000386

Zettler, I., Thielmann, I., Hilbig, B. E., \& Moshagen, M. (2020). The Nomological Net of the HEXACO Model of Personality: A Large-scale Meta-analytic Investigation. Perspectives on Psychological Science. 